\title{
Direct Observation of the Xenon Physisorption Process in Mesopores by Combining In Situ Anomalous Small-Angle X-ray Scattering and X-ray Absorption Spectroscopy
}

Eike Gericke, Dirk Wallacher, Robert Wendt, Giorgia Greco, Michael Krumrey, Simone Raoux, Armin Hoell,* and Simone Mascotto*

Cite This: J. Phys. Chem. Lett. 2021, 12, 4018-4023

Read Online

ABSTRACT: The morphology and structural changes of confined matter are still far from being understood. This report deals with the development of a novel in situ method based on the combination of anomalous small-angle X-ray scattering (ASAXS) and X-ray absorption near edge structure (XANES) spectroscopy to directly probe the evolution of the xenon adsorbate phase in mesoporous silicon during gas adsorption at $165 \mathrm{~K}$. The interface area and size evolution of the confined xenon phase were determined via ASAXS demonstrating that filling and emptying the pores follow two distinct mechanisms. The mass density of the confined xenon was found to decrease prior to pore emptying. XANES analyses showed that Xe exists in two different states when confined in mesopores. This combination of methods provides a smart new tool for the study of nanoconfined matter for catalysis, gas, and energy storage applications.

$\mathrm{T}_{\mathrm{h}}$ he study of condensed matter confined in mesoporous hosts has attracted the interest of the scientific community for decades. As a result of the extensive presence of interfaces compared to the bulk, materials confined in mesopores experience a massive change in their physicochemical properties (e.g., boiling point, crystal habit, diffusion, and dielectric constant). ${ }^{1-5}$ In general, the magnitude of these changes is directly correlated to the curvature of internal surfaces and the surface to volume ratio in these systems, and therefore, it is inversely proportional to the pore radius. ${ }^{6-8}$ The understanding of these phenomena is required for a broad field of applications ranging from condensed matter physics ${ }^{1,9}$ to catalysis and separation science, ${ }^{10,11}$ passing through the characterization of mesoporous hosts using gas adsorption analysis. ${ }^{2,12}$ This characterization method is based on the pore size-dependent variation of the gas-liquid phase transition of confined fluids. Within the past several years, significant progress has been made in understanding fluid confinement during physisorption. A major contribution was provided by computational methods, ${ }^{6,13-15}$ and gas adsorption experiments, ${ }^{16-19}$ although these approaches were necessarily limited by the assumption of simple pore structures and of macroscopic physicochemical parameters of the confined adsorbate. ${ }^{2}$ A drastic improvement came with the advent of in situ small-angle X-ray and neutron scattering (SAXS and SANS, respectively) studies. ${ }^{20-23}$ Exploiting the contrast matching (CM) between the adsorbate and the porous matrix, i.e., both phases possess identical scattering length density (SLD) or the electron density, in the cases of SANS and SAXS, respectively, we directly observed the evolution of the gas adsorption and desorption process in mesopores and analyzed the material pore structure.

Despite the significant contributions of the CM methods to the investigation of complex nanoporous materials such as oxides, ${ }^{23-26}$ carbon, ${ }^{23,27-29}$ and hybrid materials, ${ }^{30}$ its application is limited by experimental constraints. For SAXS, it is challenging to find absorbable fluids with exactly the same electron density as the porous host material to fulfill the CM condition. $^{22}$ In SANS, experiments feature much lower spatial resolution and require longer exposure times compared to those of SAXS. Under CM conditions, the adsorbate phase is made "invisible" to photons and/or neutrons. Therefore, in any filling stage, the scattering can be modeled by a two-phase system. The physisorption process is observed indirectly by the analysis of the remaining unfilled pore scattering. Thus, the observable scattering intensity decreases significantly for high filling grades and finally disappears at $100 \%$ filling. As a consequence, the most significant steps of the physisorption process (e.g., capillary condensation) have to be interpreted using poorly resolved curves, leading to limited understanding. ${ }^{22}$ Therefore, a method for the direct investigation of adsorbate phase evolution is highly desirable. Such a method

Received: February 19, 2021

Accepted: March 21, 2021

Published: April 20, 2021 
would provide evidence to improve our understanding of gas adsorption and condensation phenomena of fluids confined in mesopores.

In this report, we show how the evolution of adsorbed xenon on mesoporous silicon at its boiling point $(T=165 \mathrm{~K})$ can be directly followed by in situ anomalous small-angle X-ray scattering (ASAXS) and X-ray adsorption near edge structure (XANES) spectroscopy measurements. These analyses were performed at Physikalisch-Technische Bundesanstalt (PTB's) four-crystal monochromator beamline ${ }^{31}$ at the HelmholtzZentrum Berlin (HZB) synchrotron radiation facility BESSY II. For ASAXS, scattering curves are recorded at five X-ray energies below the $\mathrm{Xe}_{3} \mathrm{X}$-ray absorption edge of $4784 \mathrm{eV}$ to extract the resonant scattering contribution, which contains nanostructural information related only to the adsorbed Xe. Xray absorbance and XANES measurements at the $\mathrm{Xe} \mathrm{L}_{3}$ and $\mathrm{L}_{2}$ $(5104 \mathrm{eV})$ edges determined the amount and mass density of adsorbed Xe and the presence of different adsorbate species in confinement, respectively.

The mesoporous silicon membrane was prepared by electrochemical oxidation (anodization). ${ }^{32}$ Scanning electron microscopy (SEM) analysis shows disordered, corrugated elongated pores that are approximately $10 \mathrm{~nm}$ in diameter (Figure 1a,b). The pore diameter was estimated from the pore

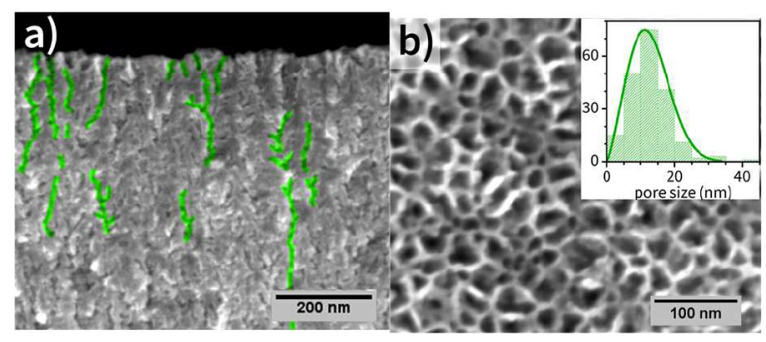

Figure 1. SEM images of the porous Si membrane: (a) side view with selected anisotropic pores colored green and (b) top view along with the pore size distribution in the inset.

area assuming the pore openings to be circular. Nitrogen physisorption confirmed these results (see the Supporting Information). During the in situ physisorption experiment using $\mathrm{Xe}$ as the probe gas, SAXS was measured at a fixed energy of $4680 \mathrm{eV}$ for 16 physisorption steps.

In Figure $2 \mathrm{a}$, the SAXS curves for selected relative pressures $\left(p / p_{0}\right)$ are displayed, where reference pressure $p_{0}$ is the equilibrium vapor pressure of bulk Xe at $165 \mathrm{~K}$. A monotonic decrease in the scattering intensity is observed due to the decreasing scattering contrast during pore filling. Exclusively, when $p / p_{0}=0.97$, the shape of the SAXS curve changes at low $q$ values, likely associated with the filling of the large pore openings (Figure $1 \mathrm{~b}$ ). Total recovery of the initial scattering intensity was observed during desorption (Figure 2b), indicating the full reversibility of the physisorption process. A comprehensive analysis of SAXS data is generally carried out for two-phase systems. ${ }^{33}$ As three components ( $\mathrm{Si}, \mathrm{Xe}$, and voids) with distinct scattering contrast are present here, SAXS could hardly provide further structural information during the physisorption process. Therefore, ASAXS was applied at the Xe $\mathrm{L}_{3}$ edge for each physisorption step.

In ASAXS, the photon energy $E$ is dependent on the anomalous dispersion of atomic scattering factor $f(E)$ (eq 1 ) of an element near its absorption edge. This effect is used to separate the scattering contribution of the resonantly behaving

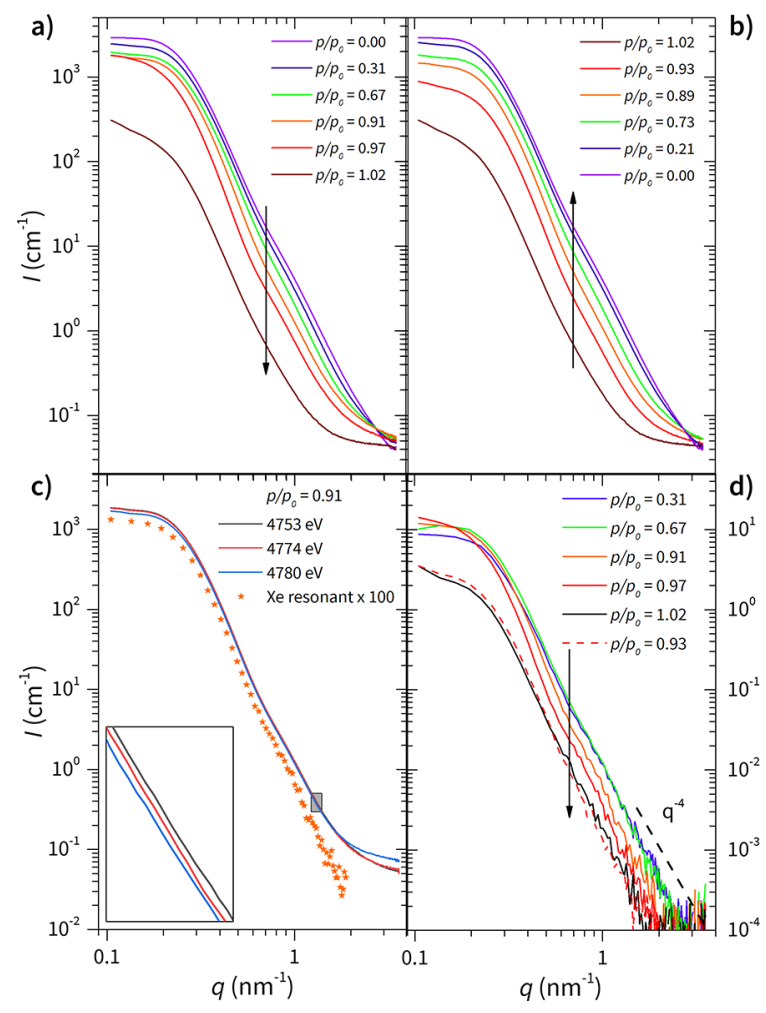

Figure 2. SAXS curves measured during (a) adsorption and (b) desorption at selected $p / p_{0}$ values. (c) Exemplary ASAXS scattering data. Scattering is measured at three $\mathrm{X}$-ray energies as given in the plot. The inset shows a close-up of the area marked by a gray rectangle. The deviation between the three curves is determined by the anomalous effect. (d) Xe resonant scattering curves for Xe adsorption and desorption at selected $p / p_{0}$ values.

element from the energy-independent scattering contribution of all other and thus nonresonant elements in the sample. ${ }^{34}$

$$
f(E)=f_{0}+f^{\prime}(E)+i f^{\prime \prime}(E)
$$

where $f_{0}$ is the number of electrons of the element and $f^{\prime}(E)$ and $f^{\prime \prime}(E)$ are the energy-dependent real and imaginary parts of the atomic scattering factor, respectively. Therefore, scattering intensity $I(q, E)$ of a SAXS pattern becomes energy-dependent. A set of scattering curves measured at least at three different energies $I\left(q, E_{i}\right)$ can be transformed into a set of three energyindependent scattering contributions by applying the so-called Stuhrmann method: ${ }^{35}$

$$
I\left(q, E_{i}\right)=I_{0}(q)+2 f^{\prime}\left(E_{i}\right) I_{0 \mathrm{R}}(q)+\left[f^{\prime 2}(E)+f^{\prime \prime 2}(E)\right] I_{\mathrm{R}}(q)
$$

The resonant scattering contribution $I_{\mathrm{R}}(q)$ contains information about the spatial arrangement of $\mathrm{Xe}$ only. ${ }^{36}$ $I_{0}(q)$ corresponds to the scattering behavior at energies far from any absorption edge of the elements present in the sample, and $I_{0 \mathrm{R}}(q)$ is the cross term of both.

Figure $2 c$ shows three SAXS curves measured at 4753, 4774, and $4780 \mathrm{eV}$ at $p / p_{0}=0.91$. The differences between the scattering intensities (inset of Figure $2 c$ ) originate from the anomalous effect. ${ }^{35,37-39}$ The resonant curves $I_{\mathrm{R}}(q)$ represent a two-phase system, made of $\mathrm{Xe}$ and its surroundings [pore space and Si matrix (Scheme 1)]. The resonant curves also denote a change in shape at high pressures, corroborating the findings of SAXS. The $q^{-4}$ decay of the resonant curves at high $q$ values indicates the $\mathrm{Xe}-$ and $\mathrm{Si}-$ matrix interfaces to be well- 
Scheme 1. Graphical Representation of the Nanostructures Detected by the Xe Resonant Curve

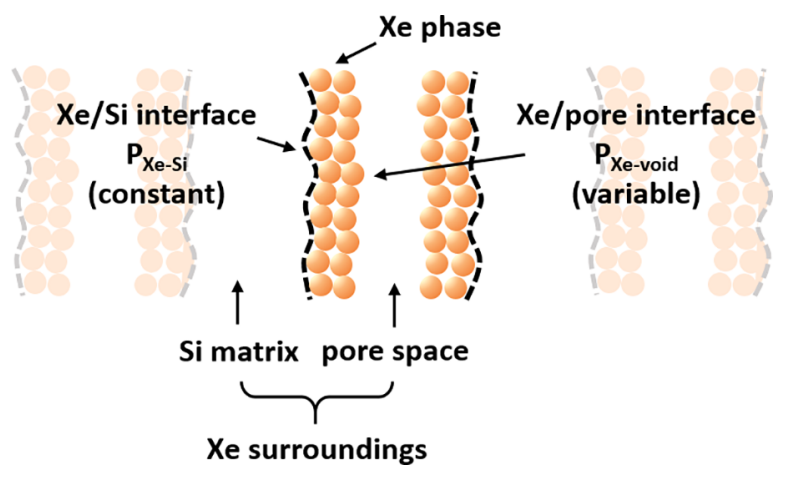

defined and smooth. The resonant curves, therefore, fulfill completely the Porod law: ${ }^{40}$

$$
\lim _{q \rightarrow \infty} I_{\mathrm{R}}(q)=\frac{P}{q^{4}}=\frac{2 \pi(\Delta \rho)^{2}}{q^{4}} S_{\mathrm{V}}
$$

where $(\Delta \rho)^{2}$ is the squared difference of the electron density between Xe and the "surroundings" (Scheme 1). P is the Porod constant, which is proportional to volume-specific surface area $S_{\mathrm{V}}$ of the two-phase system Xe surroundings.

The variation of $P$ from the resonant curves during $\mathrm{Xe}$ adsorption and desorption is displayed in Figure 3a. $P$ consists

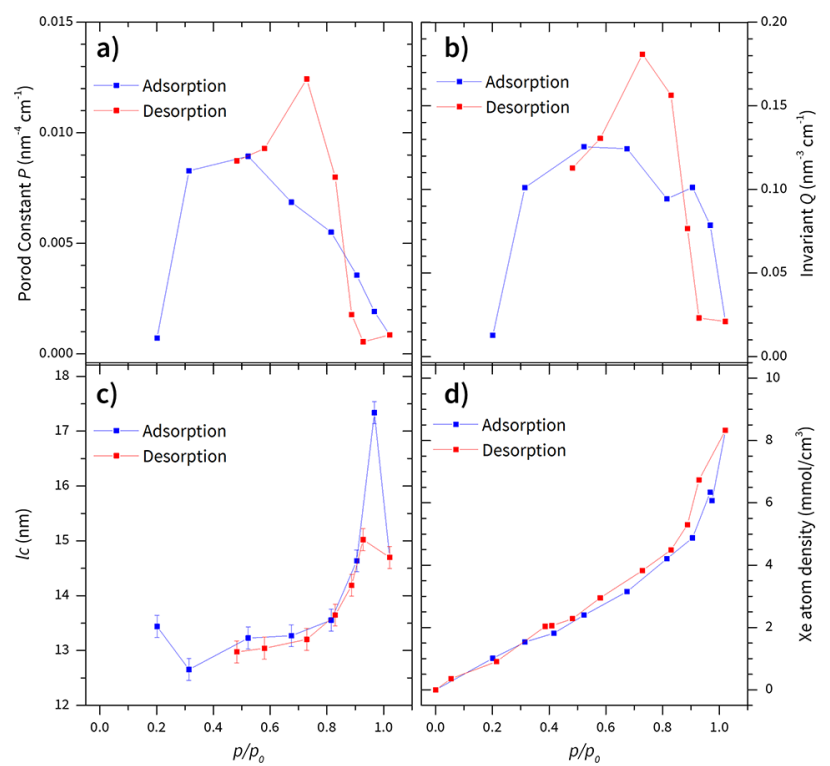

Figure 3. (a) Porod constant plot showing the variation of the interface area of the inner pore surface during Xe physisorption. (b) Invariant plot indicating the change in the pore volume ratio filled with Xe during physisorption. (c) Correlation length plot displaying the variation of the Xe film thickness. (d) Xe physisorption isotherm from the X-ray absorbance.

of two parts: the total interface between $\mathrm{Xe}$ and the Si matrix, i.e., the outer pore surface $\left(P_{\mathrm{Xe}-\mathrm{Si}}\right)$, and the inner interface between $\mathrm{Xe}$ and the remaining pore space, i.e., the inner pore surface $\left[P_{\mathrm{Xe}-\text { void }}(\right.$ Scheme 1$\left.)\right]$ :

$$
P=P_{\mathrm{Xe}-\mathrm{Si}}+P_{\mathrm{Xe}-\text { void }}
$$

where $P_{\mathrm{Xe}-\mathrm{Si}}$ remains constant during the whole physisorption process. Thus, the changes observed in Figure $3 \mathrm{a}$ are ascribed to the variation in $P_{\mathrm{Xe-void}}$ only. Consequently, the value of $P$ at the adsorption starting $\left(p / p_{0}=0.2\right)$ and filled state $\left(p / p_{0}=1\right)$ can be interpreted as the total outer surface of the pores (Scheme 2a, I and IV).

During adsorption, the initial increase in the inner pore surface area is related to the formation of $\mathrm{Xe}$ multilayers (Scheme 2a, II). For relative pressures higher than $p / p_{0}=0.5$, the substantial increase in Xe volume in the multilayer regime and during capillary condensation leads to a continuous decrease in the inner pore surface area, as expected (Scheme $2 \mathrm{a}, \mathrm{III})$. A different trend during desorption is observed. The value of $P$ does not change significantly in the first desorption step; i.e., the pores are still filled with $\mathrm{Xe}$. When the interface area starts to increase again (Scheme $2 \mathrm{aV}$ ), the Xe desorption process begins, indicated by an abrupt increase in $P$. $P$ stabilizes at values close to those of the adsorption at $p / p_{0}=$ 0.6. Such behavior can be associated with the formation of a concave meniscus at the gas-liquid interface. Once the liquid phase has evaporated, further desorption from the multilayers occurs, as expected from the theoretical predictions. ${ }^{2}$ The difference in the variation of $P$ between $p / p_{0}$ values of 0.7 and 0.9 for adsorption and desorption provides direct experimental insights into the different mechanisms of capillary condensation and pore emptying. ${ }^{2}$ The volume increase of the metastable Xe films during adsorption explains the decrease of the adsorbate interface (Scheme 2a, III). The sudden increase observed during desorption is likely caused by the receding meniscus of the already existing gas-liquid interface (Scheme 2a, V).

The analysis of the resonant scattering curves also enables us to retrieve Xe-specific correlation length $l_{c}$ from ${ }^{40}$

$$
\begin{aligned}
& l_{\mathrm{c}}=\pi \frac{\int_{0}^{\infty} q I_{\mathrm{R}}(q) \mathrm{d} q}{Q} \\
& \text { with } Q=\int_{0}^{\infty} q^{2} I_{\mathrm{R}}(q) \mathrm{d} q=2 \pi^{2}(\Delta \rho)^{2} \phi(1-\phi)
\end{aligned}
$$

where $Q$ is the invariant of the resonant scattering curves and depends on Xe volume fraction $\phi$ (Figure $3 b$ ). The correlation length represents the weighted average length of the system and can be described as

$$
l_{\mathrm{c}}=l_{\mathrm{cXe}-\mathrm{Si}}+l_{\mathrm{c}_{\mathrm{Xe}-\mathrm{void}}}
$$

where $l_{\mathrm{cXe}-\mathrm{Si}}$ represents the distance connecting two pore walls and $l_{\text {cXe-void }}$ the distance within the pore space (Scheme $2 \mathrm{~b}$ ). Similar to the case of $P, l_{\mathrm{cXe}-\mathrm{Si}}$ remains constant, and the changes observed in Figure $3 \mathrm{c}$ are ascribed to the variation of $l_{\text {cXe-void }}$ only, thus providing the detailed evolution of the average size of the Xe adsorbate domains during the whole physisorption process and particularly at high filling rates. The starting values of $l_{\mathrm{c}}$ at approximately $13 \mathrm{~nm}$ account for only the contribution of $l_{\mathrm{cXe}-\mathrm{Si}}$ (Scheme $2 \mathrm{~b}, \mathrm{I}$ ), in good agreement with the pore size calculation of the Si membrane (Figure 1). The increase observed for the points in the multilayer region is ascribed to the forming Xe layer (Scheme $2 \mathrm{~b}, \mathrm{II}$ ). For $p / p_{0}$ values of $>0.8$, the observed exponential increase in $l_{c}$ explains well the pore filling during capillary condensation (Scheme $2 \mathrm{~b}$, III). The highest value reached at $p / p_{0}=0.97$ corresponds to the filling of large pore structures (Scheme 2a, IV), which can be ascribed to the pore openings (Figure $1 \mathrm{~b}$ ) as previously mentioned. This interpretation is sustained by the change in shape of the $\mathrm{Xe}$ resonant curve at low scattering vectors 
Scheme 2. (a) Graphical Representation from the Side of the Evolution of the Inner Pore Surface during the Xe Physisorption Process and (b) Graphical Representation from the Top of the Xe Film Thickness Evolution Along with the Two Characteristic Correlation Lengths $\left(l_{\mathrm{cXe}-\mathrm{Si}}\right.$ and $l_{\mathrm{cXe}-\mathrm{void}}$, colored black and blue, respectively)

a)
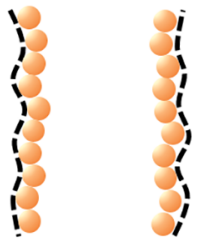

I

b)

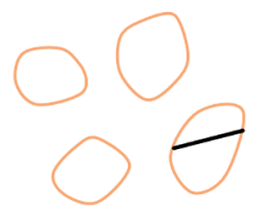

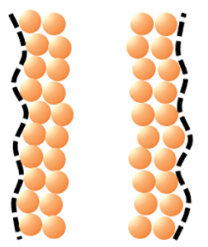

II

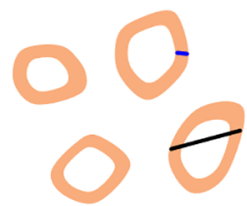

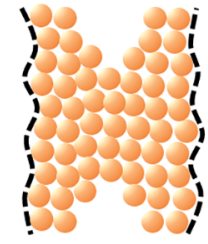

III

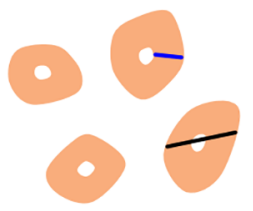

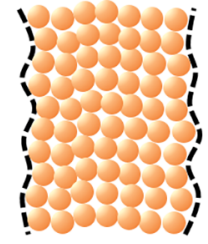

IV

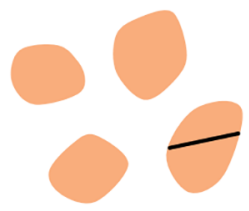

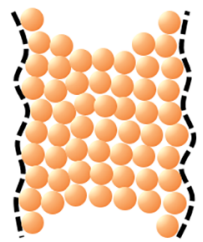

V

$p / p_{0}=1$

(Figure $2 \mathrm{~d}$ ). In the filled state $\left(p / p_{0}=1\right)$, one would expect that $l_{\mathrm{c}}$ reaches the value of $l_{\mathrm{cXe}-\mathrm{Si}}$ as the available inner pore space is depleted (Scheme $2 \mathrm{~b}, \mathrm{IV}$ ). The slightly higher value found infers the contribution of the large pore openings (Figure $1 \mathrm{~b}$ ). The $l_{\mathrm{c}}$ value does not change for the first point of desorption at $p / p_{0}=0.93$, indicating that the pore space is still filled, as also found for the Porod constant (Figure 3a). The subsequent points at lower relative pressures follow the adsorption values, showing the decrease in the thickness of the Xe film (Scheme 2b, V).

From the X-ray absorbance, we determined the amount of adsorbed Xe (Figure $3 \mathrm{~d}$ ). The hysteresis loop from $p / p_{0}=0.8$ indicates the gas-liquid phase transition inside the pores. This result agrees with the $l_{c}$ analysis (Figure $3 \mathrm{c}$ ) and shows that the resonant curves deliver reliable information about the direct adsorbate evolution, especially at high filling grades.

From the X-ray absorbance, the mass density of liquid Xe in the confined state was obtained (see the Supporting Information). The density $\rho=(2.8 \pm 0.2) \mathrm{g} / \mathrm{cm}^{3}$ at $p / p_{0}=$ 1 agrees with the nominal density of liquid Xe $(\rho=2.94 \mathrm{~g} /$ $\left.\mathrm{cm}^{3}\right) .{ }^{41}$ Interestingly, the value of the first point of desorption shows a lower density of $(2.2 \pm 0.2) \mathrm{g} / \mathrm{cm}^{3}$. From the ASAXS analysis, we found that for both points the pores are completely filled with Xe. Therefore, the density of liquid Xe decreases prior to pore emptying. So far, only computational studies could predict such a density loss. ${ }^{14,42,43}$ In mesoporous silicon, this effect was explained by an expansion of the liquid throughout the pore structure. ${ }^{42}$ Also, the Laplace pressure that originated in liquid $\mathrm{Xe}$ upon formation of the concave menisci during desorption might reasonably contribute to this effect. $^{44,45}$ The experimental determination of the adsorbate density opens interesting perspectives in particular for the investigation of the desorption mechanism of ink-bottle pore geometries. $^{46-49}$

In addition, XANES spectra were recorded at the $\mathrm{L}_{3}$ and $\mathrm{L}_{2}$ absorption edges of $\mathrm{Xe}$ at relative pressure values of $0.31,0.67$, and 0.93 (Figure 4 and Figure SI 2). White-line broadening at the $\mathrm{L}_{3}$ edge increases from $5.6 \mathrm{eV}$ to $5.7 \mathrm{eV}$ and $6.7 \mathrm{eV}$. Such broadening can be associated with the increased collision rate in the adsorbate, providing an additional way to follow $\mathrm{Xe}$ condensation. At the $\mathrm{L}_{2}$ edge at $(5103.3 \pm 0.5 \mathrm{eV})$, a distinct

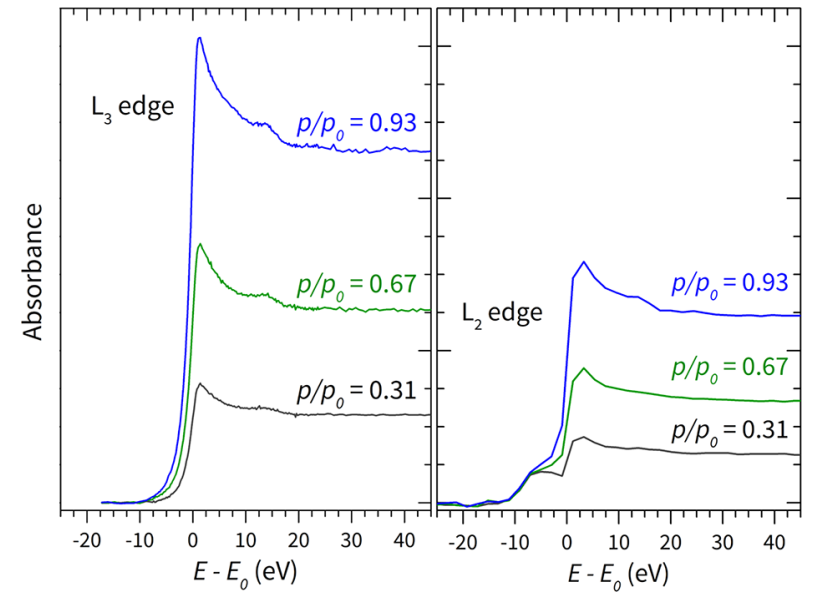

Figure 4. Normalized XANES spectra measured at $p / p_{0}$ values of 0.31 (black) and 0.67 (green) during adsorption and 0.93 (blue) during desorption for the $\mathrm{Xe} \mathrm{L}_{3}$ and $\mathrm{L}_{2}$ edges.

signal $4.6 \mathrm{eV}$ below the edge is found, which does not belong to bulk Xe. ${ }^{50}$ The $\mathrm{L}_{2}$ edge jump increases with an increase in $p / p_{0}$, while the pre-edge signal remains. Hence, this effect is therefore indicative of the formation of two distinct species of $\mathrm{Xe}$ confined in mesopores. EXAFS spectra at the $\mathrm{L}_{3}$ edge, however, could not provide further insights into the Xe local structure due to experimental limitations (see the Supporting Information).

In conclusion, we presented a novel approach for following the physisorption process of $\mathrm{Xe}$ in mesopores in situ using combined ASAXS and XANES experiments at $165 \mathrm{~K}$. We observed for the first time the evolution of the Xe adsorbate phase in confinement in direct and unambiguous fashion. From ASAXS, the variation of the Xe interface area and the size evolution of the Xe domains were determined even at high filling grades. These analyses proved the existence of different filling and emptying mechanisms of Xe in the pores. From the $\mathrm{X}$-ray absorbance, we showed that the Xe mass density decreases prior to pore emptying, confirming the predictions of computational studies. Using XANES, we observed the presence of two distinct Xe species in the pores. 
This novel and promising method investigates confinement effects by looking directly at the physicochemical changes of the confined matter. The unique combination of the complementary techniques ASAXS and XANES during in situ physisorption experiments opens to a hitherto unexplored field of science. Thus, a comprehensive understanding of both the structure and the morphology of confined matter for different applications such as adsorption-induced deformation, ${ }^{51}$ ionic electrosorption in energy storage, ${ }^{52}$ and confined catalysis $^{53}$ will be possible.

\section{ASSOCIATED CONTENT}

\section{SI Supporting Information}

The Supporting Information is available free of charge at https://pubs.acs.org/doi/10.1021/acs.jpclett.1c00557.

Experimental details, nitrogen physisorption, mass density calculation, ASAXS method and analysis, and XANES and EXAFS analysis (PDF)

\section{AUTHOR INFORMATION}

\section{Corresponding Authors}

Armin Hoell - Helmholtz-Zentrum Berlin, 14109 Berlin, Germany; 이이이.org/0000-0002-7080-8393;

Email: hoell@helmholtz-berlin.de

Simone Mascotto - Institut für Anorganische und Angewandte Chemie, Universität Hamburg, 20146 Hamburg, Germany; 이이.org/0000-0002-3503-6391; Email: simone.mascotto@chemie.uni-hamburg.de

\section{Authors}

Eike Gericke - Helmholtz-Zentrum Berlin, 14109 Berlin, Germany; Institut für Chemie, Humboldt-Universität zu Berlin, 12489 Berlin, Germany

Dirk Wallacher - Helmholtz-Zentrum Berlin, 14109 Berlin, Germany

Robert Wendt - Helmholtz-Zentrum Berlin, 14109 Berlin, Germany; 이이이.org/0000-0001-8480-4775

Giorgia Greco - Helmholtz-Zentrum Berlin, 14109 Berlin, Germany; 10 orcid.org/0000-0002-4612-5840

Michael Krumrey - Physikalisch-Technische Bundesanstalt (PTB), 10587 Berlin, Germany; 이잉.org/0000-00019591-5462

Simone Raoux - Helmholtz-Zentrum Berlin, 14109 Berlin, Germany; Institut für Physik, Humboldt-Universität zu Berlin, 12489 Berlin, Germany

Complete contact information is available at: https://pubs.acs.org/10.1021/acs.jpclett.1c00557

\section{Notes}

The authors declare no competing financial interest.

\section{ACKNOWLEDGMENTS}

The authors gratefully acknowledge the support of the PTB beamline staff and Nico Grimm (HZB). The authors thank Tommy Hofmann for preparing the porous Si sample and for scientific discussions about the results. The authors are thankful to Klaus Effland for constructing the in situ sample environment and for technical assistance during the experiment. Holger Kropf (HZB) supported the SEM measurements. Michael Fröba is gratefully acknowledged for the fruitful discussions.

\section{REFERENCES}

(1) Huber, P. Soft Matter in Hard Confinement: Phase Transition Thermodynamics, Structure, Texture, Diffusion and Flow in Nanoporous Media. J. Phys.: Condens. Matter 2015, 27, 103102.

(2) Thommes, M. Physical Adsorption Characterization of Nanoporous Materials. Chem. Ing. Tech. 2010, 82, 1059-1073.

(3) Steiger, M. Crystal Growth in Porous Materials - II: Influence of Crystal Size on the Crystallization Pressure. J. Cryst. Growth 2005, 282, 470-481.

(4) Sugahara, A.; Ando, Y.; Kajiyama, S.; Yazawa, K.; Gotoh, K.; Otani, M.; Okubo, M.; Yamada, A. Negative Dielectric Constant of Water Confined in Nanosheets. Nat. Commun. 2019, 10, 850.

(5) Valiullin, R.; Naumov, S.; Galvosas, P.; Kärger, J.; Woo, H.-J.; Porcheron, F.; Monson, P. A. Exploration of Molecular Dynamics during Transient Sorption of Fluids in Mesoporous Materials. Nature 2006, 443, 965-968.

(6) Monson, P. A. Understanding Adsorption/Desorption Hysteresis for Fluids in Mesoporous Materials Using Simple Molecular Models and Classical Density Functional Theory. Microporous Mesoporous Mater. 2012, 160, 47-66.

(7) Neimark, A. V.; Ravikovitch, P. I.; Grün, M.; Schüth, F.; Unger, K. K. Pore Size Analysis of MCM-41 Type Adsorbents by Means of Nitrogen and Argon Adsorption. J. Colloid Interface Sci. 1998, 207, 159-169.

(8) Ravikovitch, P. I.; Neimark, A. V. Characterization of Micro- and Mesoporosity in SBA-15 Materials from Adsorption Data by the NLDFT Method. J. Phys. Chem. B 2001, 105, 6817-6823.

(9) Balzer, C.; Cimino, R. T.; Gor, G. Y.; Neimark, A. V.; Reichenauer, G. Deformation of Microporous Carbons during N2, Ar, and $\mathrm{CO} 2$ Adsorption: Insight from the Density Functional Theory. Langmuir 2016, 32, 8265-8274.

(10) Melnikov, S. M.; Höltzel, A.; Seidel-Morgenstern, A.; Tallarek, U. Composition, Structure, and Mobility of Water-Acetonitrile Mixtures in a Silica Nanopore Studied by Molecular Dynamics Simulations. Anal. Chem. 2011, 83, 2569-2575.

(11) Falkowska, M.; Bowron, D. T.; Manyar, H.; Youngs, T. G. A.; Hardacre, C. Confinement Effects on the Benzene Orientational Structure. Angew. Chem., Int. Ed. 2018, 57, 4565-4570.

(12) Thommes, M.; Kaneko, K.; Neimark, A. V.; Olivier, J. P.; Rodriguez-Reinoso, F.; Rouquerol, J.; Sing, K. S. W. Physisorption of Gases, with Special Reference to the Evaluation of Surface Area and Pore Size Distribution (IUPAC Technical Report). Pure Appl. Chem. 2015, 87, 1051-1069.

(13) Neimark, A. V.; Ravikovitch, P. I.; Vishnyakov, A. Adsorption Hysteresis in Nanopores. Phys. Rev. E: Stat., Nonlinear, Soft Matter Phys. 2000, 62, R1493-R1496.

(14) Neimark, A. V.; Lin, Y.; Ravikovitch, P. I.; Thommes, M. Quenched Solid Density Functional Theory and Pore Size Analysis of Micro-Mesoporous Carbons. Carbon 2009, 47, 1617-1628.

(15) Rasmussen, C. J.; Vishnyakov, A.; Thommes, M.; Smarsly, B. M.; Kleitz, F.; Neimark, A. V. Cavitation in Metastable Liquid Nitrogen Confined to Nanoscale Pores. Langmuir 2010, 26, 1014710157.

(16) Zeng, Y.; Tan, S. J.; Do, D. D.; Nicholson, D. Hysteresis and Scanning Curves in Linear Arrays of Mesopores with Two Cavities and Three Necks. Colloids Surf., A 2016, 496, 52-62.

(17) Thommes, M.; Morell, J.; Cychosz, K. A.; Fröba, M. Combining Nitrogen, Argon, and Water Adsorption for Advanced Characterization of Ordered Mesoporous Carbons (CMKs) and Periodic Mesoporous Organosilicas (PMOs). Langmuir 2013, 29, 14893-14902.

(18) Guillet-Nicolas, R.; Bérubé, F.; Thommes, M.; Janicke, M. T.; Kleitz, F. Selectively Tuned Pore Condensation and Hysteresis Behavior in Mesoporous SBA-15 Silica: Correlating Material Synthesis to Advanced Gas Adsorption Analysis. J. Phys. Chem. C 2017, 121, 24505-24526.

(19) Thommes, M.; Smarsly, B.; Groenewolt, M.; Ravikovitch, P. I.; Neimark, A. V. Adsorption Hysteresis of Nitrogen and Argon in Pore 
Networks and Characterization of Novel Micro- and Mesoporous Silicas. Langmuir 2006, 22, 756-764.

(20) Hoinkis, E. Small Angle Neutron Scattering Study of C6D6 Condensation in a Mesoporous Glass. Langmuir 1996, 12, 42994302.

(21) Smarsly, B.; Göltner, C.; Antonietti, M.; Ruland, W.; Hoinkis, E. SANS Investigation of Nitrogen Sorption in Porous Silica. J. Phys. Chem. B 2001, 105, 831-840.

(22) Zickler, G. A.; Jähnert, S.; Wagermaier, W.; Funari, S. S.; Findenegg, G. H.; Paris, O. Physisorbed Films in Periodic Mesoporous Silica Studied by in Situ Synchrotron Small-Angle Diffraction. Phys. Rev. B 2006, 73, 184109.

(23) Mascotto, S.; Kuzmicz, D.; Wallacher, D.; Siebenbürger, M.; Clemens, D.; Risse, S.; Yuan, J.; Antonietti, M.; Ballauff, M. Poly(Ionic Liquid)-Derived Nanoporous Carbon Analyzed by Combination of Gas Physisorption and Small-Angle Neutron Scattering. Carbon 2015, 82, 425-435.

(24) Mascotto, S.; Wallacher, D.; Brandt, A.; Hauss, T.; Thommes, M.; Zickler, G. A.; Funari, S. S.; Timmann, A.; Smarsly, B. M. Analysis of Microporosity in Ordered Mesoporous Hierarchically Structured Silica by Combining Physisorption With in Situ Small-Angle Scattering (SAXS and SANS). Langmuir 2009, 25, 12670-12681.

(25) Jähnert, S.; Müter, D.; Prass, J.; Zickler, G. A.; Paris, O.; Findenegg, G. H. Pore Structure and Fluid Sorption in Ordered Mesoporous Silica. I. Experimental Study by in Situ Small-Angle xRay Scattering. J. Phys. Chem. C 2009, 113, 15201-15210.

(26) Stoeckel, D.; Wallacher, D.; Zickler, G. A.; Perlich, J.; Tallarek, U.; Smarsly, B. M. Coherent Analysis of Disordered Mesoporous Adsorbents Using Small Angle X-Ray Scattering and Physisorption Experiments. Phys. Chem. Chem. Phys. 2014, 16, 6583.

(27) Badaczewski, F.; Loeh, M. O.; Pfaff, T.; Dobrotka, S.; Wallacher, D.; Clemens, D.; Metz, J.; Smarsly, B. M. Peering into the Structural Evolution of Glass-like Carbons Derived from Phenolic Resin by Combining Small-Angle Neutron Scattering with an Advanced Evaluation Method for Wide-Angle X-Ray Scattering. Carbon 2019, 141, 169-181.

(28) Scholz, J.; Kayaalp, B.; Juhl, A.; Clemens, D.; Fröba, M.; Mascotto, S. Severe Loss of Confined Sulfur in Nanoporous Carbon for Li-S Batteries Under Wetting Conditions. ACS Energy Lett. 2018, 3, 387-392.

(29) Petzold, A.; Juhl, A.; Scholz, J.; Ufer, B.; Goerigk, G.; Fröba, M.; Ballauff, M.; Mascotto, S. Distribution of Sulfur in Carbon/Sulfur Nanocomposites Analyzed by Small-Angle X-Ray Scattering. Langmuir 2016, 32, 2780-2786.

(30) Mascotto, S.; Wallacher, D.; Kuschel, A.; Polarz, S.; Zickler, G. A.; Timmann, A.; Smarsly, B. M. Adsorption in Periodically Ordered Mesoporous Organosilica Materials Studied by in Situ Small-Angle XRay Scattering and Small-Angle Neutron Scattering. Langmuir 2010, 26, 6583-6592.

(31) Krumrey, M.; Ulm, G. High-Accuracy Detector Calibration at the PTB Four-Crystal Monochromator Beamline. Nucl. Instrum. Methods Phys. Res., Sect. A 2001, 467-468, 1175-1178.

(32) Zhang, X. G. Morphology and Formation Mechanisms of Porous Silicon. J. Electrochem. Soc. 2004, 151, C69.

(33) Smarsly, B. M.; Kaper, H.; Mascotto, S.; Weidmann, C. Charakterisierung Mesoporöser Materialien Mittels Kleinwinkelstreuung (SAXS/SANS). Chem. Ing. Tech. 2010, 82, 823-828.

(34) Haubold, H.-G.; Wang, X. H.; Jungbluth, H.; Goerigk, G.; Schilling, W. In Situ Anomalous Small-Angle X-Ray Scattering and XRay Absorption near-Edge Structure Investigation of Catalyst Structures and Reactions. J. Mol. Struct. 1996, 383, 283-289.

(35) Stuhrmann, H. B. Resonance Scattering in Macromolecular Structure Research. Adv. Polym. Sci. 1985, 67, 123-163.

(36) Hoell, A.; Tatchev, D.; Haas, S.; Haug, J.; Boesecke, P. On the Determination of Partial Structure Functions in Small-Angle Scattering Exemplified by $\mathrm{Al}_{89} \mathrm{Ni}_{6} \mathrm{La}_{5}$ Alloy. J. Appl. Crystallogr. 2009, 42, 323-325.
(37) Cromer, D. T.; Liberman, D. Relativistic Calculation of Anomalous Scattering Factors for X Rays. J. Chem. Phys. 1970, 53, 1891-1898.

(38) Tatchev, D. Structure Analysis of Multiphase Systems by Anomalous Small-Angle X-Ray Scattering. Philos. Mag. 2008, 88, 1751-1772.

(39) Le, T. T.; Pistidda, C.; Puszkiel, J. A.; Castro Riglos, M. V.; Karimi, F.; Skibsted, J.; GharibDoust, S. P.; Richter, B.; Emmler, T.; Milanese, C.; et al. Design of a Nanometric AlTi Additive for MgB2 Based Reactive Hydride Composites with Superior Kinetic Properties. J. Phys. Chem. C 2018, 122, 7642-7655.

(40) Glatter, O.; Kratky, O. Small-Angle X-ray Scattering; Academic Press Inc.: London, 1982; Vol. 1.

(41) Heynes, W. M.; Lide, D. R.; Bruno, T. J. Handbook of Chemistry and Physics, 97th ed.; CRC Press Taylor \& Francis Group: Boca Raton, FL, 2017.

(42) Naumov, S.; Khokhlov, A.; Valiullin, R.; Kärger, J.; Monson, P. A. Understanding Capillary Condensation and Hysteresis in Porous Silicon: Network Effects within Independent Pores. Phys. Rev. E: Stat., Nonlinear, Soft Matter Phys. 2008, 78, 060601.

(43) Edison, J. R.; Monson, P. A. Dynamic Mean Field Theory for Lattice Gas Models of Fluids Confined in Porous Materials: Higher Order Theory Based on the Bethe-Peierls and Path Probability Method Approximations. J. Chem. Phys. 2014, 141, 024706.

(44) Schappert, K.; Pelster, R. Influence of the Laplace Pressure on the Elasticity of Argon in Nanopores. Europhys. Lett. 2014, 105, 56001-p1.

(45) Gor, G. Y.; Paris, O.; Prass, J.; Russo, P. A.; Ribeiro Carrott, M. M. L.; Neimark, A. V. Adsorption of N-Pentane on Mesoporous Silica and Adsorbent Deformation. Langmuir 2013, 29, 8601-8608.

(46) Ravikovitch, P. I.; Neimark, A. V. Experimental Confirmation of Different Mechanisms of Evaporation from Ink-Bottle Type Pores: Equilibrium, Pore Blocking, and Cavitation. Langmuir 2002, 18, 9830-9837.

(47) Vishnyakov, A.; Neimark, A. V. Monte Carlo Simulation Test of Pore Blocking Effects. Langmuir 2003, 19, 3240-3247.

(48) Wallacher, D.; Künzner, N.; Kovalev, D.; Knorr, N.; Knorr, K. Capillary Condensation in Linear Mesopores of Different Shape. Phys. Rev. Lett. 2004, 92, 195704.

(49) Naumov, S.; Valiullin, R.; Kärger, J.; Monson, P. A. Understanding Adsorption and Desorption Processes in Mesoporous Materials with Independent Disordered Channels. Phys. Rev. E: Stat., Nonlinear, Soft Matter Phys. 2009, 80, 031607.

(50) Watanabe, T. Measurement of the L Absorption Spectra of Xenon. Phys. Rev. 1965, 137, A1380.

(51) Gor, G. Y.; Huber, P.; Bernstein, N. Adsorption-Induced Deformation of Nanoporous Materials-A Review. Appl. Phys. Rev. 2017, 4, 011303

(52) Koczwara, C.; Prehal, C.; Haas, S.; Boesecke, P.; Huesing, N.; Paris, O. Towards Real-Time Ion-Specific Structural Sensitivity in Nanoporous Carbon Electrodes Using In Situ Anomalous SmallAngle X-Ray Scattering. ACS Appl. Mater. Interfaces 2019, 11, 4221442220 .

(53) Shifa, T. A.; Vomiero, A. Confined Catalysis: Progress and Prospects in Energy Conversion. Adv. Energy Mater. 2019, 9, 1902307. 